\title{
Original Research \\ Quality of facility-based family planning services for adolescents in Malawi: Findings from a national census of health facilities
}

\author{
Vinitha Jayachandran ${ }^{1}$, Gertrude Chapotera ${ }^{1}$, William Stones ${ }^{1,2,3}$ \\ 1. School of Public Health and Family Medicine, College of Medicine, University of Malawi, Blantyre, Malawi \\ 2. Department of Obstetrics and Gynaecology, College of Medicine, University of Malawi, Blantyre, Malawi \\ 3. School of Medicine, University of St Andrews, Fife, United Kingdom
}

Correspondence to: William Stones (rws6@st-andrews.ac.uk)

\section{Background}

The main objective of this study was to describe the quality, in terms of provision and experience of care, of facility-based family planning services for adolescents compared to older clients in Malawi.

Methods

Secondary data analysis was performed on data obtained from the Service Provision Assessment survey 2013-14, a census of all formal health facilities in the country. For the present study the inclusion criterion was that the client's age was recorded in the data set, which gave a weighted total of 1388 observations of consultations, reflecting provision of care, and client exit interviews, reflecting experience of care.

Results

The youngest clients (age group 13 to 19 years) had twice the odds of reporting a better experience of care compared to clients aged 26 and older (odds ratio [OR] 2.03, 95\% confidence interval [C] 1.15 to 3.54, P = 0.013). The standard of observed provision was low, typically with half or more of the mandated elements of care omitted. Compared with clients aged over 25, provision of care was slightly better for adolescents, with a coefficient of 4.56 on a percentage scale $(95 \%$ CI 0.90 to $8.23, \mathrm{P}=0.015)$ and a coefficient of 2.33 for those aged 20-25 (95\% CI 0.21 to 4.44, $\mathrm{P}=0.032)$. Clients seen in facilities under nongovernmental management had better provision of care compared to government facilities, with a coefficient of 12.35 (95\% CI 6.70 to 18.01, P $<0.001)$; care was worse for clients seen in clinics compared to hospitals (coefficient $-6.88,95 \% \mathrm{CI}-11.41$ to $-2.35, \mathrm{P}=0.003$ ) and also for clients seen by health surveillance assistants compared to those seen by a clinician (coefficient $-9.41,95 \% \mathrm{CI}-15.53$ to $-3.29, \mathrm{P}=0.003$ ).

\section{Conclusions}

Quality of care for adolescents attending facility-based family planning services was slightly better than for older clients, but this is overshadowed by the finding of a low standard of care overall. Health system strengthening, especially at the clinic level, is a policy and programming priority that will contribute to adolescent reproductive health in Malawi.

\section{Introduction}

Access to family planning services in Malawi has steadily increased, as evidenced by serial population surveys that reflect increased use of modern methods of contraception among women aged 15 to 49 years. ${ }^{1}$ Modern contraceptive use has now reached $58 \%$ according to the recently released Key Indicators Report of the 2015-16 Malawi Demographic and Health Survey (DHS). ${ }^{2}$ In a context of overall high fertility, the Malawi MDG Endline Survey carried out in 2013 and 2014 showed high birth rates among young women aged 15 to 19 years. Age-specific fertility was 143 per 1000 women in this age group, compared to 248 per 1000 women aged 20 to 24 years and 218 per 1000 women aged 25 to 29 years. ${ }^{3}$ The corresponding new findings from the 2015 16 report (per 1000 women) are 136 among 15- to 19-yearolds, 216 among 20- to 24-year-olds, and 193 among 25- to 29 -year-olds, ${ }^{2}$ suggesting that access to contraception has increased across all age groups in recent years. The lower age-specific fertility among adolescents is partly explained by the larger proportion of unmarried and sexually abstinent individuals in this age group. However, among adolescents who are married or in union, the percentage using modern contraception is low, at around 39\%, compared with $57 \%$ of 20 - to 24 - year-olds, ${ }^{3}$ and this age differential is still present in the most recently available survey findings. ${ }^{2}$ The concept of "unmet need" may be difficult to apply meaningfully to adolescents, especially those in the younger age groups, but recognising that adolescent pregnancy is associated with excess obstetric risk, ${ }^{4}$ a range of programmatic interventions has been brought forward through initiatives of the Malawi government, development partners, and faith-based and community organisations, focusing on delaying sexual debut, retaining girls in school and extending access to contraception through family planning services.

The Malawi government initiated the Youth Friendly Health Services (YFHS) programme in 2007 to enhance access to sexual and reproductive health (SRH) services and recently restated the importance of such provision: "Ensuring access to comprehensive, youth-friendly SRH services will help young people delay childbearing until they are ready and avoid HIV and other sexually transmitted diseases. This will enable them to stay in school and to participate in the productive workforce, benefiting them, their families and the nation as a whole. " Notwithstanding these initiatives, young people in Malawi, especially girls, still face multiple risks and challenges related both to their sexual and reproductive health (for example, obstetric risks associated with teenage pregnancy) and access to lifetime opportunities (for example, school dropout following early sexual debut and childbearing). While it may be unrealistic to anticipate that facility-based services, such as family planning clinics, could transform the social norms and conditions that lead to early sexual debut and teenage pregnancy, there is evidence that young people do look to health facilities for services: in the 2014 evaluation of the Youth Friendly Health Services initiative, it was noted that, among young people, public facilities were the preferred source for contraception for 55\% of male and $72 \%$ of female respondents. ${ }^{6}$ Thus, in parallel with 
community mobilisation, educational, and social initiatives, it is essential that health facilities are in a position to respond to the sexual and reproductive health needs of young people. Quality of health service provision has increasingly been recognised as a key determinant of uptake by clients and acceptability in communities. With regard to family planning services, six key elements of quality have formed the basis for monitoring and evaluation using facility surveys: choice of methods, information given to clients, technical competence, interpersonal relations, follow-up and continuity mechanisms, and an appropriate constellation of services. ${ }^{7}$ To enable analyses that explore client and contextual determinants, informative summary measures of quality are needed. A useful conceptualisation is to consider variables contributing to the objective content of care (such asavailability of equipment, technical competence, and adherence to best clinical practice) as components of "provision of care", and variables contributing to the client's actual experience (such as interpersonal communication, information provision, and privacy and confidentiality) as components of "experience of care". 8

In this study we examined facility-based family planning services in Malawi, aiming to describe the care provided to adolescents and to identify potential disparities in service provision related to client age. We also aimed to gain insights into service quality, taking into account both the provision and experience of care.

\section{Methods \\ Data}

We used data from the 2013-14 Malawi Service Provision Assessment. This was a census of all formal health facilities in the country. These included public facilities, those run by private practitioners, faith-based facilities, nongovernmental organisation facilities, and those managed by corporate entities. Facility types included hospitals, health centres, dispensaries, and health posts. The methods and tools used in the census are described in detail in the survey report ${ }^{9}$ and comprised facility inventories across a range of clinical services and interviews with providers at all 997 facilities. Where appropriate, clinics and clients were available during survey visits, observations of outpatient consultations, and exit interviews with clients attending for antenatal, family planning, and curative child health services. Additionally, observations of delivery and newborn care were undertaken.

Informed consent was sought for observation of consultations and participation in exit interviews. For the present study we used anonymised data files made available for research purposes by the DHS Program. The Institutional Review Board of ICF International, Inc. reviewed and approved the Demographic and Health Surveys Project Phase VII, and the 2013-14 Malawi Service Provision Assessment is categorised under that approval. The Institutional Review Board of ICF International complied with the United States Department of Health and Human Services regulations for the protection of human research subjects.

During the survey, 1464 family planning consultations were observed and exit interviews were conducted with the same clients at 369 facilities. For the present study the inclusion criterion was that the client's age was recorded in the data set, which gave a weighted total of 1388 cases for analysis.

\section{Analysis}

We used the statistical package Stata 14 (StataCorp LP,
College Station, Texas, USA). Data files for facility, provider, and client, relating to family planning services and outpatient visits, were merged and variables of interest were tabulated.

\section{Dependent variables}

We constructed two scales for quality of care based on a conceptual framework that considers provision of care and experience of care. ${ }^{8}$ From the schedule of observations of family planning consultations, there were 26 items that were not specific to particular family planning methods. These items were used to construct the scale for "provision of care". Items included whether enquiry was made about reproductive history, breastfeeding, and fertility intentions; whether the blood pressure was measured; whether visual aids were used; and how fully documentation was completed. These items had "yes/no" response options and "yes" responses were summed to generate the score. For presentation of results, this scale was expressed as a percentage, with $100 \%$ representing an optimal consultation. For "experience of care" we selected 15 of 32 items from the exit interview questionnaire. Items were selected to reflect the client's experience rather than the details of the particular methods offered. These included explanation of method use, side effects, waiting time, ability to discuss problems, explanations received, privacy, cleanliness, and how clients reported they were treated. These were recoded from the original categorical responses to numeric values. Summing of the item responses resulted in a score out of 30 , with 30/30 representing the best possible experience of care. Based on the observed skewed distribution of results, the score was dichotomised, close to the median for use in logistic regression models, into categories of "better experience of care" and "worse experience of care".

\section{Independent variables}

For the analysis, where client age was recorded for family planning clients, individuals were categorised by age into three groups, labelled "adolescent" for those aged under 20 years of age, ${ }^{10}$ "youth" for those aged 20 to 25 years, and "adult" for those aged 26 years or older. Exclusion of male respondents was not intended but the survey consultations and exit interview data set proved to include only female clients. Other independent variables were facility location, type, and management authority; provider professional status, gender, and recent family planning training experience; and client educational status.

\section{Analytical methods}

Following initial cross tabulations, bivariate associations between the quality scores, age group, and other geographical, provider-related, and facility-related explanatory variables were examined. We then developed multiple linear regression and logistic regression models for associations between age groups and other independent variables and the provision of care and experience of care scores. In all tabulations and analyses, weights were applied and analyses took into account the complex survey design, with the facility as the primary sampling unit. Regression coefficients, odds ratios (ORs), associated probabilities, and 95\% confidence intervals (CIs) were estimated.

\section{Results}

Characteristics of the female study population are shown in Table 1. Of the 1388 respondents for whom age was available, $126(9.1 \%)$ were adolescents, $621(44.7 \%)$ were youths, and $642(46.2 \%)$ were adults. 
Table 1: Participants with age recorded who consented to observation of their consultation and an exit interview, by facility, provider, and client characteristics

\begin{tabular}{|c|c|c|c|c|c|c|}
\hline \multirow{3}{*}{ Characteristics } & \multicolumn{6}{|c|}{ Participants (weighted, total 1388) } \\
\hline & \multicolumn{2}{|c|}{ Adolescent } & \multicolumn{2}{|c|}{ Youth } & \multicolumn{2}{|c|}{ Adult } \\
\hline & $\mathbf{n}$ & $\%$ & $\mathbf{n}$ & $\%$ & $\mathbf{n}$ & $\%$ \\
\hline \multicolumn{7}{|l|}{ Location of facility } \\
\hline Urban & 45 & 8.7 & 238 & 46.4 & 230 & 44.9 \\
\hline Rural & 81 & 9.3 & 383 & 43.8 & 412 & 47.0 \\
\hline \multicolumn{7}{|l|}{ Facility type } \\
\hline Hospital & 51 & 8.7 & 277 & 47.0 & 261 & 44.2 \\
\hline Health centre & 61 & 9.3 & 292 & 44.4 & 305 & 46.3 \\
\hline Dispensary & 5 & 16.1 & 11 & 37.4 & 13 & 46.5 \\
\hline Clinic & 9 & 7.6 & 42 & 36.7 & 63 & 55.7 \\
\hline \multicolumn{7}{|l|}{ Facility management authority } \\
\hline Government & 96 & 8.7 & 507 & 45.7 & 507 & 45.7 \\
\hline Christian Health Association of Malawi & 19 & 13.3 & 67 & 46.6 & 57 & 40.1 \\
\hline Private & 5 & 9.0 & 23 & 40.4 & 29 & 50.7 \\
\hline Nongovernmental organisation & 3 & 7.1 & 12 & 27.7 & 29 & 65.2 \\
\hline Company & 3 & 7.4 & 13 & 36.0 & 20 & 56.6 \\
\hline \multicolumn{7}{|l|}{ Service provider profession } \\
\hline Clinician & 2 & 2.6 & 27 & 36.0 & 46 & 61.4 \\
\hline Nurse & 113 & 9.2 & 557 & 45.6 & 552 & 45.2 \\
\hline Health surveillance assistant & 11 & 12.4 & 37 & 40.6 & 43 & 47.0 \\
\hline \multicolumn{7}{|l|}{ Service provider gender } \\
\hline Male & 40 & 10.6 & 163 & 42.7 & 178 & 46.7 \\
\hline Female & 86 & 8.5 & 458 & 45.5 & 463 & 46.0 \\
\hline \multicolumn{7}{|l|}{ Service provider family planning training } \\
\hline Within previous 3 years & 87 & 8.8 & 448 & 45.1 & 459 & 46.2 \\
\hline More than 3 years prior or never & 39 & 9.8 & 173 & 43.9 & 183 & 46.4 \\
\hline \multicolumn{7}{|l|}{ Client education } \\
\hline No school attendance & 8 & 4.8 & 50 & 29.6 & 111 & 65.6 \\
\hline Primary & 96 & 10.8 & 389 & 43.8 & 404 & 45.4 \\
\hline Secondary & 22 & 6.7 & 180 & 55.7 & 122 & 37.7 \\
\hline Higher education & 0 & 0 & 2 & 29.7 & 5 & 70.3 \\
\hline Total & 129 & 9.1 & 602 & 44.7 & 666 & 46.2 \\
\hline
\end{tabular}

The distribution of observation scores by age group is illustrated in Figure 1, and multiple linear regression results for selected explanatory variables relating to facility, provider, and client characteristics are shown in Table 2. Overall, the standard of observed care provision was low, typically with half or more of the elements of care omitted across all sectors of care and for all types of client. However, the gaps in observed care were evenly distributed across all the age groups. Provision of care was slightly worse for clients aged 26 years and above compared to adolescents and clients aged 20 to 25 years. Observed care was also worse for those seen in clinics compared to hospitals and for clients seen by health surveillance assistants (HSAs) compared to clients seen by a clinician. The facility location, provider's gender, and the provider's history of family planning-related training did not

Figure 1: Observation score (percent) by age group

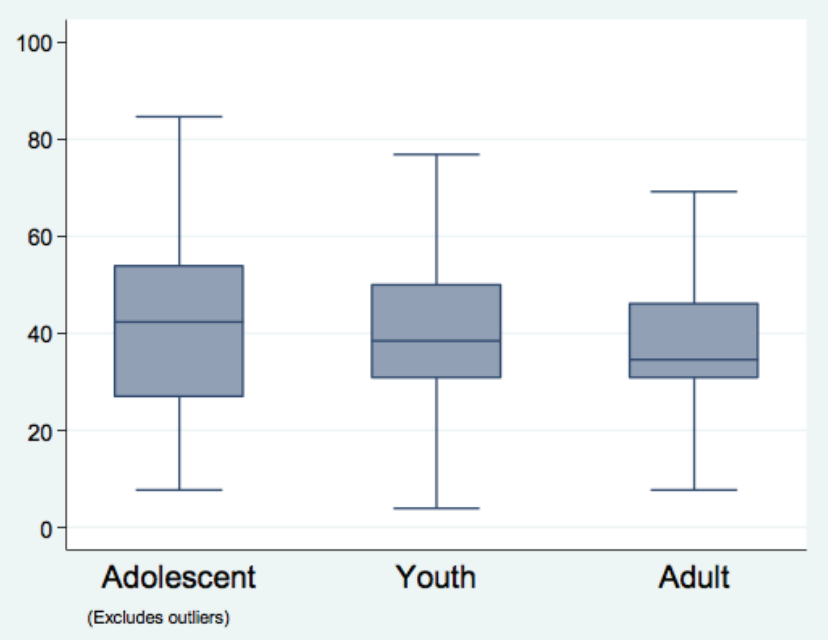

http://dx.doi.org/10.4314/mmj.v28i2.4 influence the quality of provision of care observed. Clients seen in facilities managed by nongovernmental organisations had somewhat better provision of care compared to government facilities, with a positive coefficient of 12 on the percentage scale (95\% CI 6.7 to $18.0, \mathrm{P}<0.001)$.

Experience of care scores were skewed to higher response levels (median 27, interquartile range 24 to 30 ) and were divided into categories of "better experience" and "worse experience" close to the median for analysis. The distribution of scores by age group is illustrated in Figure 2 and multiple logistic regression findings are presented in Table 3. Only the age of the client was found to influence the experience of care. Other variables examined were nonsignificant. The youngest age group of clients (13 to 19) had twice the odds of a better experience of care compared to clients in the oldest age group (OR 2.03, 95\% CI 1.15 to 3.54, $\mathrm{P}=0.013$ ).

Table 2: "Provision of care" multiple linear regression parameters for independent variables representing facility, provider and client characteristics

\begin{tabular}{|c|c|c|c|c|}
\hline \multirow{2}{*}{ Variable } & \multirow{2}{*}{ Coefficient } & \multirow{2}{*}{ P value } & \multicolumn{2}{|c|}{ 95\% Confidence Interval } \\
\hline & & & Lower & Upper \\
\hline \multicolumn{5}{|l|}{ Client age group (years) } \\
\hline 13-19 & 4.56 & 0.015 & 0.90 & 8.23 \\
\hline $20-25$ & 2.33 & 0.032 & 0.21 & 4.44 \\
\hline $26+$ & \multicolumn{4}{|c|}{ Reference } \\
\hline \multicolumn{5}{|l|}{ Client education } \\
\hline No school attendance & \multicolumn{4}{|c|}{ Reference } \\
\hline Primary & 0.98 & 0.413 & -1.37 & 3.33 \\
\hline Secondary & 2.41 & 0.139 & -0.79 & 5.61 \\
\hline Higher education & 6.11 & 0.324 & -6.06 & 18.28 \\
\hline \multicolumn{5}{|l|}{ Service provider profession } \\
\hline Clinician & \multicolumn{4}{|c|}{ Reference } \\
\hline Nurse & 0.43 & 0.862 & -4.46 & 5.33 \\
\hline Health surveillance assistant & -9.41 & 0.003 & -15.53 & -3.29 \\
\hline \multicolumn{5}{|l|}{ Service provider gender } \\
\hline Male & \multicolumn{4}{|c|}{ Reference } \\
\hline Female & -0.35 & 0.815 & -3.31 & 2.60 \\
\hline \multicolumn{5}{|l|}{ Service provider family planning training } \\
\hline Within previous 3 years & \multicolumn{4}{|c|}{ Reference } \\
\hline More than 3 years prior or never & -1.98 & 0.220 & -5.15 & 1.19 \\
\hline \multicolumn{5}{|l|}{ Facility location } \\
\hline Urban & \multicolumn{4}{|c|}{ Reference } \\
\hline Rural & -2.44 & 0.265 & -6.75 & 1.85 \\
\hline \multicolumn{5}{|l|}{ Facility type } \\
\hline Hospital & \multicolumn{4}{|c|}{ Reference } \\
\hline Health centre & -3.20 & 0.121 & -7.24 & 0.84 \\
\hline Dispensary & -1.57 & 0.632 & -8.01 & 4.87 \\
\hline Clinic & -6.88 & 0.003 & -11.41 & -2.35 \\
\hline \multicolumn{5}{|l|}{ Facility management authority } \\
\hline Government & \multicolumn{4}{|c|}{ Reference } \\
\hline Christian Health Association of Malawi & -1.25 & 0.529 & -5.15 & 2.65 \\
\hline Private & -1.43 & 0.523 & -5.81 & 2.96 \\
\hline Nongovernmental organisation & 12.35 & $<0.001$ & 6.70 & 18.01 \\
\hline Company & 2.34 & 0.462 & -3.90 & 8.58 \\
\hline
\end{tabular}

\section{Discussion}

The study hypothesis, that adolescents are at risk of poor quality of care relative to other family planning clients, is not supported by our analysis. Indeed, adolescents actually reported slightly more favourable experiences of care and this was confirmed by observations of consultations. These analytical findings from a national census of health facilities need to be interpreted against an overall picture of suboptimal quality of service provision: even while being observed by survey staff, providers across all sectors still omitted many essential components of an adequate consultation for all age groups of clients. Thus, strategies to improve quality of care in facility-based family planning services need to tackle provider behaviour and clinical standards as a priority. From the present study, clinical standards emerge as a more pressing concern than potential bias against at-risk groups, 
Figure 2: Exit score by age group

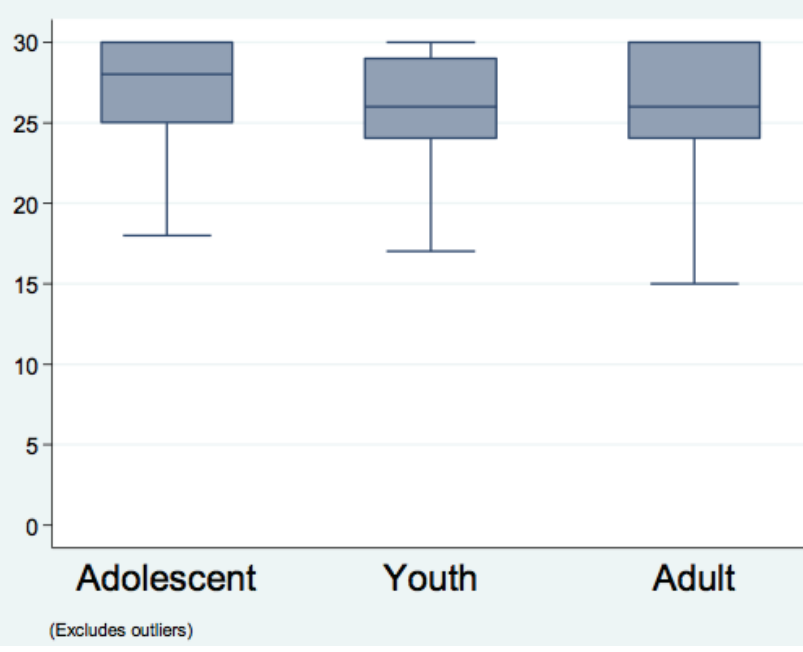

such as adolescents, for which we did not find supporting evidence. Whether staff had received recent training or not did not influence the findings. While beyond the scope of our analysis, it is likely that effective facility management with supportive supervision, including regular observation of consultations to assess compliance with clinical standards, can build good consulting behavioural habits. Furthermore, we were unable to assess service provision for young men, owing to their absence from this part of the survey.

With regard to applicability of the present work to interventions to improve clinical standards, our findings are consistent with those of a study reporting the impact of a quality improvement intervention in district hospitals in Malawi. ${ }^{11}$ In the quality improvement study, to compare quality of family planning provision during 32 consultations at "control" and "intervention" hospitals, 120 items were rated. "Control" consultations had a mean score of $70.5 / 120(59 \%)$ compared to a mean of $89 / 120(74 \%)$ at "intervention" sites, suggesting that observation ratings of this type are sensitive to change.

We found that facilities under the managing authority of nongovernmental organisations demonstrated better provision of care than facilities under government authority. It is possible that this reflects the fee-for-service model of provision at nongovernmental facilities, but aspects of facility governance, discipline, and accountability may also play a part. Factors such as workload and availability of equipment and supplies may also explain some of the observed differences. Further work is needed to explore gains in adherence to clinical standards that could be made from identifying the key aspects of the service models that result in higher quality provision and experience of care that can be generalised to other sectors. While not part of our original hypothesis, our findings raise questions about the role of health surveillance assistants in facility-based provision of family planning services. Their participation may have arisen as part of a "task shifting" or "task sharing" approach, but it would appear that this may not be a good solution if their presence is associated with reduced standards of provision. Further studies are needed to determine whether the statistical effect noted in our analysis is genuine.

The experience of care domain of quality of care presented challenges in interpretation in this study. Overall, clients of all ages were inclined to give positive responses to most questions even when the rating of the content of the observed consultation was low. Possible explanations are that clients have limited knowledge of what is supposed to happen http://dx.doi.org/10.4314/mmj.v28i2.4 during a clinical encounter, or that norms of social courtesy preclude respondents from sharing negative opinions. In particular, the concept of client satisfaction is problematic in this setting: clearly we cannot assume satisfaction on the basis of the absence of reported problems with a consultation. The issue of low expectations was highlighted in a study of maternity clients in Malawi, ${ }^{12}$ and this certainly colours the interpretation of reported satisfaction. In other similar settings it has been possible to obtain detailed and indeed highly critical feedback from clients; for example, the work on disrespect and abuse during clinical care using very specific questions. ${ }^{13}$ These reports confirm that approaches that include specific questions and allow for probing in more depth are the most informative. In planning future largescale facility surveys, it might be a better use of resources to reduce the number of exit interviews but make them more in-depth.

The analytical approach taken in the present study was to examine differences in provision and experience of care across subgroups. The scores developed, especially those used to assess provision of care, also have the potential for use as a means of benchmarking or accrediting health facilities as having attained a certain standard of clinical quality. It is unrealistic to expect $100 \%$ compliance with the set of observation standards, but further work could examine how application of a specific threshold, such as $80 \%$, might prove appropriate in recognising quality provision. Involving communities and users so that they are aware of the performance of their local hospital or clinic, in relation to established standards, could be a means of enhancing accountability and constructive demand for improvement in service quality. It is possible that such an approach might lead initially to an unintended fall in levels of client satisfaction

Table 3: "Experience of care" score category (better versus worse experience): multiple logistic regression parameters for independent variables representing facility, provider, and client characteristics

\begin{tabular}{|c|c|c|c|c|}
\hline \multirow{2}{*}{ Variable } & \multirow{2}{*}{ Odds ratio } & \multirow{2}{*}{ P value } & \multicolumn{2}{|c|}{ 95\% Confidence interval } \\
\hline & & & Lower & Upper \\
\hline \multicolumn{5}{|l|}{ Client age group (years) } \\
\hline 13-19 & 2.03 & 0.013 & 1.15 & 3.54 \\
\hline $20-25$ & 1.06 & 0.702 & 0.78 & 1.45 \\
\hline $26+$ & \multicolumn{4}{|c|}{ Reference } \\
\hline \multicolumn{5}{|l|}{ Client education } \\
\hline No school attendance & \multicolumn{4}{|c|}{ Reference } \\
\hline Primary & 1.06 & 0.777 & 0.72 & 1.57 \\
\hline Secondary & 1.17 & 0.590 & 0.67 & 2.05 \\
\hline Higher education & 1.05 & 0.962 & 0.13 & 8.23 \\
\hline \multicolumn{5}{|l|}{ Service provider profession } \\
\hline Clinician & \multicolumn{4}{|c|}{ Reference } \\
\hline Nurse & 1.18 & 0.616 & 0.62 & 2.25 \\
\hline Health surveillance assistant & 1.00 & 1.000 & 0.43 & 2.33 \\
\hline \multicolumn{5}{|l|}{ Service provider gender } \\
\hline Male & \multicolumn{4}{|c|}{ Reference } \\
\hline Female & 0.97 & 0.895 & 0.65 & 1.45 \\
\hline \multicolumn{5}{|l|}{ Service provider family planning training } \\
\hline Within previous 3 years & \multicolumn{4}{|c|}{ Reference } \\
\hline More than 3 years prior or never & 0.87 & 0.480 & 0.59 & 1.28 \\
\hline \multicolumn{5}{|l|}{ Facility location } \\
\hline Urban & \multicolumn{4}{|c|}{ Reference } \\
\hline Rural & 1.15 & 0.610 & 0.77 & 1.96 \\
\hline \multicolumn{5}{|l|}{ Facility type } \\
\hline Hospital & \multicolumn{4}{|c|}{ Reference } \\
\hline Health centre & 0.96 & 0.873 & 0.58 & 1.59 \\
\hline Dispensary & 1.40 & 0.480 & 0.55 & 3.60 \\
\hline Clinic & 1.56 & 0.311 & 0.66 & 3.72 \\
\hline \multicolumn{5}{|l|}{ Facility management } \\
\hline Government & \multicolumn{4}{|c|}{ Reference } \\
\hline Christian Health Association of Malawi & 0.66 & 0.125 & 0.39 & 1.12 \\
\hline Private & 0.48 & 0.109 & 0.20 & 1.18 \\
\hline Nongovernmental organisation & 1.37 & 0.462 & 0.59 & 3.15 \\
\hline Company & 1.20 & 0.730 & 0.43 & 3.39 \\
\hline
\end{tabular}


as expectations are raised amid greater awareness of service gaps, but ultimately this is worthwhile as part of the journey to client-responsive, high-quality provision of services.

A recent systematic review highlighted confidentiality as a key concern of adolescents seeking contraceptive services. ${ }^{14}$ It is not clear in the current service model what this really means in terms of practical clinic arrangements, and to what extent young people can be convinced that confidentiality is a reality. For example, steps might need to be taken that allow the purpose of a clinic visit not to be obvious to local residents who may be encountered during the visit.

For adolescent sexual and reproductive health, facilitybased provision of family planning services is only one component of a comprehensive approach to health and wellbeing for young people, but these essential community and social aspects are beyond the scope of the present study. Integrating school-based educational activities, outof-school outreach, community mobilisation, and staff training in youth-friendly service provision was shown to enhance service uptake in Ghana in a formal comparison, with more limited intervention components of staff training or community mobilisation alone. ${ }^{15}$ The views of young people themselves about what aspects of service provision are the most important and how these are valued can be ascertained through formal methods, such as discrete choice experiments. ${ }^{16}$ In Ntcheu District, a discrete choice experiment carried out in 2012 suggested that the preferred service model was one that assured confidentiality as the first priority, also included HIV testing and treatment, and had a component of youth sports. ${ }^{16}$

Finally, with regard to national monitoring and evaluation and comparison with other countries, international standards for provision of health services for adolescents have been set out, ${ }^{17}$ and adolescent services are included in the World Health Organization (WHO) Service Availability and Readiness Assessment tools. ${ }^{18}$ Work is needed to integrate these standards and tools with current Health Management Information Systems (HMIS) for ongoing monitoring as well as periodic surveys, such as the Service Provision Assessments.

\section{Acknowledgements}

This research was developed at a DHS Program workshop funded by USAID Malawi. The authors gratefully acknowledge Wenjuan Wang, Paul Ametepi, and Shireen Assaf of ICF International, and Jupiter Simbeye of Chancellor College, University of Malawi for their support and advice on the analysis and manuscript. The funder had no role in the study design, analysis, or manuscript preparation, and the views expressed are those of the authors.

\section{References}

1. National Statistical Office (NSO) (Malawi), ICF Macro. Malawi Demographic and Health Survey 2010. Zomba and Calverton (MD): NSO and ICF Macro; 2011.

2. National Statistical Office (NSO) (Malawi), ICF International Malawi demographic and health survey 2015-16: key indicators report. Zomba and Rockville (MD): NSO and ICF International; 2016.

3. National Statistical Office (NSO) (Malawi). Malawi MDG endline survey 2014. Zomba; 2015.

4. Ganchimeg T, Ota E, Morisaki N, Laopaiboon M, Lumbiganon P, Zhang J, et al. Pregnancy and childbirth outcomes among adolescent mothers: a World Health Organization multicountry study. BJOG. 2014 Mar;121(s1):40-8.
5. Ministry of Economic Planning and Development (Malawi). A vision for the health and well-being of Malawi's young people [Internet]. Lilongwe: Population Reference Bureau, Ministry of Economic Planning and Development (Malawi); 2014 [cited 2015 Dec 13]. Available from: http://www.prb.org/pdf14/malawi-youth-report-2014. pdf

6. Feyisetan B, Munthali A, Benevides R, Kazembe A, Mutombo N. Evaluation of youth-friendly services in Malawi [Internet]. Washington, D.C.: USAID; 2014 [cited 2015 Dec 13]. Available from: http://www. e2aproject.org/publications-tools/pdfs/evaluation-yfhs-malawi.pdf

7. Bruce J. Fundamental elements of the quality of care: a simple framework. Stud Fam Plann. 1990;21(2):61-91.

8. Hulton LA, Matthews Z, Stones RW. A framework for the evaluation of quality of care in maternity services [Internet]. Southampton: University of Southampton; 2000 [cited 2015 Dec 23]. Available from: https://core.ac.uk/download/files/34/29877.pdf

9. Ministry of Health (Malawi), ICF International. Malawi service provision assessment (MSPA) 2013-14. Lilongwe and Rockville (MD): Ministry of Health (Malawi) and ICF International; 2014.

10. World Health Organization. Adolescence: a period needing special attention [Internet]. Health for the world's adolescents: a second chance in the second decade. Geneva: World Health Organization; 2014 [cited 2016 Feb 13]. Available from: http://apps.who.int/adolescent/seconddecade/section2

11. Rawlins BJ, Kim Y-M, Rozario AM, Bazant E, Rashidi T, Bandazi $\mathrm{SN}$, et al. Reproductive health services in Malawi: an evaluation of a quality improvement intervention. Midwifery. 2013 Jan;29(1):53-9.

12. Kumbani LC, Chirwa E, Malata A, Odland JØ, Bjune G, Ahman E, et al. Do Malawian women critically assess the quality of care? A qualitative study on women's perceptions of perinatal care at a district hospital in Malawi. Reprod Health. 2012;9(1):30.

13. Abuya T, Ndwiga C, Ritter J, Kanya L, Bellows B, Binkin N, et al. The effect of a multi-component intervention on disrespect and abuse during childbirth in Kenya. BMC Pregnancy Childbirth. 2015 Dec 22;15(1):224.

14. Williams JR, Gavin LE, Carter MW, Glass E. Client and provider perspectives on quality of care: a systematic review. Am J Prev Med. 2015;49(2):S93-106.

15. Aninanya GA, Debpuur CY, Awine T, Williams JE, Hodgson A, Howard N, et al. Effects of an Adolescent Sexual and Reproductive Health Intervention on Health Service Usage by Young People in Northern Ghana: A Community-Randomised Trial. Zeeb H, editor. PLoS One. 2015 Apr 30;10(4):e0125267.

16. Michaels-Igbokwe C, Lagarde M, Cairns J, Terris-Prestholt F, Singh $\mathrm{S}$, Darroch J, et al. Designing a package of sexual and reproductive health and HIV outreach services to meet the heterogeneous preferences of young people in Malawi: results from a discrete choice experiment. Health Econ Rev. 2015 Dec 9;5(1):9.

17. World Health Organization. Standards and criteria [Internet]. Global standards for quality health-care services for adolescents: a guide to implement a standards-driven approach to improve the quality of health care services for adolescents. Geneva: World Health Organization; 2015 [cited 2015 Dec 13]. Available from: http://apps.who.int/iris/ bitstream/10665/183935/1/9789241549332_vol1_eng.pdf

18. World Health Organization. Service availability and readiness assessment (SARA): an annual monitoring system for service delivery reference manual, version 2.2 [Internet]. Health statistics and information systems. Geneva: World Health Organization; 2015 [cited 2015 Dec 13]. Available from: http://www.who.int/healthinfo/systems/ sara_reference_manual/en/ 